\title{
Assessment of liver antioxidant status and mitochondrial membrane composition of Plasmodium berghei-infected mice treated with selected antimalarials
}

\author{
Rahmat Adetutu Adisa ${ }^{\bowtie}$ and Lateef Adegboyega Sulaimon \\ Department of Biochemistry, Faculty of Basic Medical Sciences, College of Medicine, University of Lagos, Idi-araba, P.M.B. 12003, Lagos, Nigeria
}

The present study was aimed at determining and comparing the effects of Artecxin (ART), P - Alaxin (P-ALA), Lonart (LON) and Chloroquine (CQ) on oxidative stress parameters and mitochondrial membrane composition in the course of malaria infection. Six groups of five mice each categorized as healthy control (nonparasitized non-treated group), parasitized-non-treated $(\mathrm{PnT})$, parasitized-chloroquine-treated (positive control), parasitized-Artecxin, -Lonart and -P-Alaxin-treated groups were used for the study. Hepatic antioxidant status was assessed with levels of malondialdehyde (MDA) and reduced glutathione (GSH) as well as activity of superoxide dismutase (SOD) and catalase (CAT) in the post mitochondrial and mitochondrial fractions. Mitochondrial membrane integrity was also evaluated with activity of succinate dehydrogenase and levels of phospholipids, cholesterol and proteins in the liver mitochondria. Results revealed that treatment of parasitized mice with the antimalarial drugs significantly $(p<0.05)$ decreased hepatic malondialdehyde (MDA) and mitochondrial membrane phospholipids compared to parasitized untreated group. On the other hand, significantly $(p<0.05)$ elevated succinate dehydrogenase (SDH) activity, mitochondrial membrane cholesterol level, GSH concentration, catalase (CAT) and superoxide dismutase (SOD) activity in the post mitochondrial fraction were obtained. Thus, antimalarial drugs distort mitochondrial membrane integrity and electron transfer but reduce the malaria-induced oxidative stress on the host.

Key words: Plasmodium berghei, Artecxin, Lonart, P-Alaxin; Chloroquine, oxidative stress, mitochondrial membrane fluidity

Received: 10 October, 2016; revised: 21 November, 2016; accepted: 24 November, 2016; available on-line: 09 August, 2017

e-mail: radisa22@yahoo.com; radisa@unilag.edu.ng

Abbreviations: ART, Artecxin; P-ALA, P-Alaxin; LON, Lonart; CQ Chloroquine; PnT, parasitized-non-treated; MDA, malondialdehyde; $\mathrm{GSH}$, reduced glutathione; SOD, superoxide dismutase; CAT, catalase; GSH, reduced glutathione; CAT, catalase; $S D H$, succinate dehydrogenase; ROS, reactive oxygen species; $A C T s$, artemisinin combination therapies; KCN, potassium cyanide; PMF, post mitochondrial fraction; ATP, adenosine triphosphate, AST, aspartate aminotransferase; ALP, alkaline phosphatase; ALT, alanine aminotransferase

\section{INTRODUCTION}

Malaria is an enormous public health problem worldwide and kills one to two million people every year, mostly children residing in Africa (Breman et al., 2004; Yoshida et al., 2010). Furthermore, malaria is the most lethal parasitic disease in the world, annually affecting approximately 500 million people mostly in African sub-
Saharan countries (Snow et al., 2005). Malaria infection in humans and animals is caused by the parasite Plasmodium. Several species of Plasmodium have the ability to cause malaria in animals, including rodents. Mice infected with $P$. berghei and $P$. vinckei are considered to be a comparable genetic model to humans. There is a high degree of genomic conservation, up to $99 \%$ (Pennacchio, 2003) and it is well established that mice also exhibit natural differences in susceptibility to malarial infection (Greenberg et al., 1954).

Oxidative stress is common among malaria patients (Egwunyenga et al., 2004) as a result of activation of the immune responses by malaria parasite; thereby, causing release of reactive oxygen species (ROS) (Kulkarni et al., 2003; Akanbi et al., 2009). The increase in lipid peroxidation level in malaria patients and decrease in ascorbic acid and reduced glutathione (GSH) was observed to be accountable for the development of oxidative stress in malaria patients (Loria et al., 1999). Thus, malaria infection was found to be associated with lipid peroxidation accompanying reduction in antioxidant capacity (Idonije et al., 2011). Also, the role of the liver in the transmission process of malaria infection makes the mitochondrium a vital organelle that is likely to be critically involved in the biochemical events leading to disease onset (Chicco \& Sparagna, 2007). Altered membrane composition affects mitochondrial respiration (Ohtsuka et al., 1993) as has been implicated in a variety of human diseases including Barth syndrome, ischemia, and heart failure (Joshi et al., 2009). Thus, it became imperative to evaluate the integrity of the liver mitochondrial membrane composition of the host mice in this study.

Malaria parasites are sensitive to oxidative damage and this is demonstrated by the efficacy of some antimalarial drugs such as Artemisinin compounds that are known to act by generation of ROS when administered clinically or experimentally (Farombi et al., 2003). Successful chemotherapy depends largely on the ability to exploit metabolic differences between pathogens and the host (Onyesom \& Agho, 2011). The malaria parasite has developed resistance to drugs used in the therapy of malaria, except the artemisinins (Olayemi et al., 2012).

Artemisinin Combination Therapies (ACTs) combines artemisinin derivatives with other antimalarials, including quinoline compounds, such as amodiaquine and piperaquine. The quinolines act mainly by inhibiting hematin polymerization, thus intoxicating the parasite with the ferriprotoporphyrin groups generated by haemoglobin degradation (Vennerstrom et al., 1999). Other antimalarials used in ACTs, for example, pyrimethamine, trimethoprim, lumefantrine, proguanil, inhibit the tetrahydrofolic acid cycle and thus eliminate an important cofactor for 
DNA synthesis. Despite the arsenal of drugs available for malaria treatment, the disease remains a worldwide public health problem.

Artemisinin and its derivatives exert their antimalarial effects by production of carbon-centred radicals. However, the effects of artemisinin compounds and combinations on oxidative stress parameters and mitochondrial membrane composition have neither been evaluated nor compared to some of the older drugs used in Nigeria. Thus, overall aim of this present study was to determine and compare the effects of Artecxin (32 mg dihydroartemisinin $+320 \mathrm{mg}$ piperaquine phosphate $+90 \mathrm{mg}$ trimethoprim), Lonart (80 mg Artemether + $480 \mathrm{mg} \mathrm{Lu}-$ mefantrine), P-Alaxin (40 $\mathrm{mg}$ dihydroartemisinin +320 $\mathrm{mg}$ piperaquine phosphate) and Chloroquine on oxidative stress parameters, succinate dehydrogenase activity and mitochondrial membrane composition in the course of malaria infection in mice.

\section{MATERIALS AND METHODS}

Drugs and Chemicals. Artecxin (32 mg Dihydroartemisinin, $320 \mathrm{mg}$ Piperaquine phosphate and $90 \mathrm{mg}$ Trimethoprim) was manufactured by Chongqing Tonghe Pharmaceutical Co. LTD, Chongqing, China. P-Alaxin (40 mg Dihydroartemisinin and $320 \mathrm{mg}$ Piperaquine phosphate) and Lonart (80 $\mathrm{mg}$ Artemether and $480 \mathrm{mg}$ Lumefantrine) were manufactured by Bliss GvsPharma Ltd, India. Epinephrine, Ellman's reagent (5,51-Dithiobis-2-Nitrobenzoic Acid, DTNB), Glutathione (GSH) were purchased from Sigma Aldrich Chemical Co, USA. All other chemicals were of commercially available analytical grade.

Animals Maintenance. Adult male Swiss albino mice $(20-23 \mathrm{~g})$ were obtained from the Animal House, College of Medicine, University of Lagos, Nigeria and were kept in well-ventilated standard plastic cages. The mice were acclimatized for a period of 2 weeks, maintained on standard mouse pellets (Pfizer Livestock Feeds, Lagos, Nigeria) and water ad libitum. All experiments were conducted without anaesthesia and the protocol was in conformity to the guidelines of the National Institute of Health (NIH publication 85-23, 1985) for laboratory animal care and use. The Animal Ethical Committee of the College of Medicine, University of Lagos, Nigeria, approved this research study.

Parasite Inoculation. The NK 65 strain of Plasmodium berghei used in this study was obtained from Dr. O. O. Aina of Malaria Research Laboratory, Department of Biochemistry, National Institute of Medical Research (NIMR), Yaba, Lagos, Nigeria. The mice were infected intra-peritoneally on the first day of the experiment with standard inoculum $\left(1 \times 10^{7}\right.$ Plasmodium berghei (NK-65 strain)-infected parasitized red blood cells). The animals were left for three days for incubation of the parasite which was confirmed with thick blood film stained with Giemsa stain and viewed under the microscope at $\times 100$. Furthermore, malaria parasite infection was detected by parasite count using the formula: Parasite density ( $\mathrm{p} \mu \mathrm{l}$ ) $=$ Number of parasites counted $\times 8000$ white blood cells)/Number of white blood cells counted. The parasite infected mice also presented symptoms of malaria including chills, fatigue/reduced activity, loss of appetite and weight loss. Animals with parasite density $>10000 \mathrm{p} /$ $\mu \mathrm{l}$ were selected for this study.

Experimental design and Treatment. Five healthy mice with zero level of parasitaemia and no symptoms of malaria infection served as control (Group 1) and re- ceived $10 \mathrm{ml} / \mathrm{kg}$ body weight of normal saline by oral intubation. Twenty five parasitized (Pn'T) mice were randomly divided into 5 groups of five animals each as follows:

- Group 2: Pn'T untreated mice administered $10 \mathrm{ml} / \mathrm{kg}$ body weight of normal saline.

- Group 3: PnT mice administered CQ (10.33 mg/kg body weight in normal saline).

- Group 4: PnT mice administered ART $(14.73 \mathrm{mg} / \mathrm{kg}$ body weight in normal saline).

- Group 5: Pn'T mice administered LON (9.33 mg/kg body weight in normal saline).

- Group 6: PnT mice administered P-ALA $(18 \mathrm{mg} / \mathrm{kg}$ body weight in normal saline).

All treatments were administered by oral intubation for 3 days according to manufacturer's dosing recommendation for each drug and mice were fasted overnight before and after the last dose of drug administration. The animals were weighed just before sacrifice by cervical dislocation.

Preparation of sub-cellular fractions. Harvested livers were quickly excised, rinsed in ice-cold $1.15 \% \mathrm{KCl}$, blotted and weighed. They were homogenized in ice-cold $0.25 \mathrm{M}$ sucrose in a potter- elvehjem homogenizer. The $5 \%$ homogenate was centrifuged at $2600 \mathrm{rpm}$ for $5 \mathrm{~min}$ at $4^{\circ} \mathrm{C}$. The supernatant obtained was centrifuged at $13000 \mathrm{rpm}$ for 20 minutes at $4^{\circ} \mathrm{C}$. The supernatant (post mitochondrial fractions) was aliquoted and stored at $-80^{\circ} \mathrm{C}$ while the pellet (mitochondria) was washed twice at the same speed and time (Johnson \& Lardy, 1967). The washed mitochondrial pellet was re-suspended in ice-cold $0.25 \mathrm{M}$ sucrose $(1 \mu \mathrm{l}$ sucrose per mitochondrial pellet from $10 \mathrm{mg}$ of liver). The suspension was aliquoted in eppendorf tubes and stored at $-80^{\circ} \mathrm{C}$ until required for use.

Biochemical assays. Protein concentrations were determined as described by Lowry et al. (1951) using bovine serum albumin as standard. Biomarkers of hepatic oxidative stress in mitochondrial and post mitochondrial fractions were determined.

Superoxide dismutase (SOD) activity was determined by its ability to inhibit the auto-oxidation of epinephrine at $\mathrm{pH} 10.2$ monitored by the increase in absorbance at $480 \mathrm{~nm}$ as described by Misra and Fridovich (1972). The activity of mitochondrial MnSOD was measured in the presence of $1 \mathrm{mM} \mathrm{KCN}$, and the cytosolic $\mathrm{Cu}, \mathrm{Zn} \mathrm{SOD}$ activity was determined in the absence of $\mathrm{KCN}$ (Geller $\&$ Winge, 1983). One unit of SOD activity was defined as the amount of enzyme required for 50\% inhibition of the oxidation of epinephrine to adrenochrome at 480 $\mathrm{nm} \mathrm{min}^{-1}$. The reaction mixture $(3 \mathrm{ml})$ contained $2.5 \mathrm{ml}$ of $0.05 \mathrm{M}$ sodium carbonate buffer $\mathrm{pH} 10.2,0.2 \mathrm{ml}$ of tissue homogenate $(1: 10)$ (containing SOD) and $0.3 \mathrm{ml}$ of $0.3 \mathrm{mM}$ epinephrine used to initiate the reaction. The reference cuvette contained $2.5 \mathrm{ml}$ buffer, $0.3 \mathrm{ml}$ of substrate (epinephrine) and $0.2 \mathrm{ml}$ of water. Enzyme activity was calculated by measuring the change in absorbance at $480 \mathrm{~nm}$ for $5 \mathrm{~min}$.

Reduced glutathione (GSH) level was determined using Ellman's reagent, 5,5'-dithio-bis-2-nitrobenzoic acid (DTNB) as described by Sedlak \& Lindsay (1968) and Jollow and coworkers (1974). Briefly, $0.2 \mathrm{ml}$ of sample was mixed with $1.8 \mathrm{ml}$ of distilled water and $3 \mathrm{ml}$ of precipitating reagent (4\% sulphosalicylic acid), and the mixture was allowed to stand for $10 \mathrm{~min}$. Supernatant $(0.5 \mathrm{ml})$ was withdrawn and added to $4 \mathrm{ml}$ of $0.1 \mathrm{M}$ phosphate buffer $\mathrm{pH} 7.4$ followed by $0.5 \mathrm{ml}$ of Ellman's reagent. The blank was prepared with $4 \mathrm{ml}$ of $0.1 \mathrm{M}$ phosphate buffer $\mathrm{pH} 7.4,0.5 \mathrm{ml}$ of diluted precipitating 
solution and $0.5 \mathrm{ml}$ of Ellman's reagent (DTNB). The absorbance was read within 20 min of colour development at $412 \mathrm{~nm}$ against blank using spectrophotometer. Reduced glutathione concentration was proportional to the absorbance at $412 \mathrm{~nm}$.

Catalase (CAT) activity was determined as described by Sinha (1971). $0.1 \mathrm{ml}$ of sample was mixed with $4.9 \mathrm{ml}$ of distilled water. The assay mixture contained $4 \mathrm{ml}$ of $0.2 \mathrm{M} \mathrm{H}_{2} \mathrm{O}_{2}$ and $5 \mathrm{ml}$ of $0.01 \mathrm{M}$ phosphate buffer in a $10 \mathrm{ml}$ flat bottom flask. $1 \mathrm{ml}$ of properly diluted enzyme preparation (test sample) was rapidly mixed with the reaction mixture by gentle swirling motion at room temperature. A $1 \mathrm{ml}$ portion of the reaction mixture was withdrawn and blown into a test tube containing $2 \mathrm{ml}$ of dichromate/acetic acid reagent at 60 secs intervals for $3 \mathrm{~min}$ and heated for 10 min in a boiling water. Mixture was allowed to cool and the absorbance measured with a spectrophotometer at $570 \mathrm{~nm}$.

The extent of lipid peroxidation in mitochondrial and post mitochondrial fractions was determined using standard methods described by Buege \& Aust (1978). An aliquot of $0.4 \mathrm{ml}$ of the test sample was mixed with $1.6 \mathrm{ml}$ of Tris $\mathrm{KCl}$ buffer (which was first placed into the test tube before the test sample). Then $0.5 \mathrm{ml}$ of $30 \%$ TCA was added followed by $0.5 \mathrm{ml}$ of $0.75 \%$ TBA and the mixture was placed in a water bath for $1 \mathrm{~h}$ at $90-95^{\circ} \mathrm{C}$ and subsequently cooled in an ice bath and centrifuged at $3000 \mathrm{rpm}$ for $15 \mathrm{~min}$. The clear pink supernatant was collected and absorbance measured against a reference blank of distilled water at $532 \mathrm{~nm}$ in a spectrophotometer.

Mitochondrial membrane phospholipid concentrations were analyzed as described by Chen and coworkers (1956) by adding $0.5 \mathrm{ml}$ of mitochondrial membrane to $9.5 \mathrm{ml}$ of ethanol-ether and heated to $80^{\circ} \mathrm{C}$. One $\mathrm{ml}$ of sulphuric acid in perchloric acid was added and gently heated for 45 min. Reaction mixture was cooled and 1 $\mathrm{ml}$ of distilled water was added and boiled for $15 \mathrm{sec}$. To $4 \mathrm{ml}$ of reaction mix, $4 \mathrm{ml}$ of $6 \mathrm{~N}$ sulphuric acid and $2.5 \%$ of ammonium molybdate were added and incubated for $2 \mathrm{~min}$ at $37^{\circ} \mathrm{C}$. Absorbance was read spectrophotometrically at $600 \mathrm{~nm}$ but cholesterol level was assayed with Randox Kits.

Assay of mitochondrial succinate dehydrogenase (SDH) activity. Succinate dehydrogenase activity in isolated mitochondria was assayed by the method described by King (1967). The reaction mixture contained $0.2 \mathrm{M}$ phosphate buffer, $\mathrm{pH} 7.8$ (0.375 $\mathrm{ml}), 0.045 \mathrm{M} \mathrm{KCN}(0.05 \mathrm{ml}), 0.6 \mathrm{M}$ succinate $(0.1$ $\mathrm{ml}$ ), $0.0015 \mathrm{M}$ dichlorophenolindophenol (DCIP, 0.05 $\mathrm{ml}$ ), $0.009 \mathrm{M}$ phenazinemethosulfate (PMS, $0.15 \mathrm{ml}$ ), distilled water $(2.95 \mathrm{ml})$ in a $3 \mathrm{ml}$ spectrophotometer glass cuvette. The reaction was started by the addition of $0.05 \mathrm{ml}$ of mitochondrial suspension. The change in absorbance at $600 \mathrm{~nm}(\Delta 600 \mathrm{~nm})$ was recorded at one minute intervals in a Beckman DU-640 spectrophotometer. The $\Delta 600 \mathrm{~nm}$ was converted to $\mu$ mols succinate oxidized by multiplying $\Delta 600 \mathrm{~nm}$ by 0.0476 . The unit of enzyme activity was expressed as nmol succinate oxidized/ $\min$ and the specific activity as units/mg mitochondrial protein.

Statistical analysis. Data were statistically computed using GraphPadPrism 6 Software and expressed as mean \pm S.E.M. Differences between mean values were further analyzed by Tukey Honest Significant Difference (Tukey's HSD) test and values of $P<0.05$ were considered significant.

\section{RESULTS}

\section{Oxidative stress biomarkers in liver post mitochondrial (PMF) and mitochondrial fractions of antimalarial drugs- treated $P$. berghei-infected mice}

Table 1 shows oxidative stress biomarkers in liver post mitochondrial (PMF) and mitochondrial fractions of $P$. berghei-infected and antimalarial drugs-treated mice. There was significant $(\phi<0.05)$ reduction in PMF GSH $(73 \%)$ level, catalase $(64 \%)$ and superoxide dismutase $(64 \%)$ activity in PnT-non-treated mice compared to control. Treatment of PnT -non-treated mice with CQ, ART, LON and P-ALA increased PMF levels of GSH $(66.5 \%, 150 \%, 128 \%$, and $166.6 \%)$, SOD activities $(73 \%, 98 \%, 66.7 \%$, and $83 \%)$, CAT activities $(61.5 \%, 100 \%, 69 \%, 73 \%)$, respectively compared to PnT -non-treated mice. Mitochondrial SOD activities also decreased by $72 \%$ in the PnT -non-treated mice compared to control; while the antimalarial treatments similarly increased this enzyme activity by 70, 184, 64 and $39 \%$, respectively. On the contrary, mitochondrial and PMF levels of MDA were increased significantly $(P<0.05)$ by 580.8 and $209 \%$, respectively in Pn'T-nontreated mice. However, treatment with antimalarials decreased these levels by $71.5,54,70,66 \%$ in mitochondria and 50, 55, 21.6, and 58\%, in PMF, respectively compared to PnT-untreated mice. The highest decrease caused by treatment with CQ and LON was not significantly different $(p>0.05)$ between those two but significantly different $(p>0.05)$ from others in the mitochondria.

Table 1. Oxidative stress markers in liver post mitochondrial and mitochondrial fractions of $P$. berghei-infected mice treated with therapeutic doses of ART, CQ, LON and P-ALA

\begin{tabular}{|c|c|c|c|c|c|c|}
\hline Treatments & $\mathrm{GSH}^{\Omega}$ & $\begin{array}{l}\text { PMF } \\
\text { SOD }^{a}\end{array}$ & $\mathrm{CAT}^{\mu}$ & $\mathrm{MDA}^{\pi}$ & $\begin{array}{l}\text { Mitochondria } \\
\text { MDA }^{\pi}\end{array}$ & $\mathrm{SOD}^{a}$ \\
\hline Control & $30.00 \pm 1.29^{a}$ & $1.67 \pm 0.13^{a}$ & $0.72 \pm 0.06^{a}$ & $1.20 \pm 0.51^{\mathrm{a}}$ & $0.52 \pm 0.05^{a}$ & $2.28 \pm 0.51^{a}$ \\
\hline PnT & $8.08 \pm 0.74^{b}$ & $0.60 \pm 0.04^{b}$ & $0.26 \pm 0.02^{b}$ & $3.71 \pm 0.60^{\mathrm{b}}$ & $3.54 \pm 0.28^{b}$ & $0.64 \pm 0.08^{b}$ \\
\hline $\mathrm{PnT}+\mathrm{CQ}$ & $21.53 \pm 0.67 c$ & $1.04 \pm 0.04 c$ & $0.42 \pm 0.02^{c}$ & $1.86 \pm 0.89^{a}$ & $1.01 \pm 0.08^{c}$ & $1.09 \pm 0.20^{c}$ \\
\hline $\mathrm{PnT}+\mathrm{ART}$ & $20.22 \pm 1.08^{c}$ & $1.19 \pm 0.06^{c}$ & $0.52 \pm 0.03^{c}$ & $1.67 \pm 0.55^{\mathrm{a}}$ & $1.63 \pm 0.12^{d}$ & $1.82 \pm 0.12^{c}$ \\
\hline $\mathrm{PnT}+\mathrm{LON}$ & $18.46 \pm 0.54$ & $1.00 \pm 0.03^{c}$ & $0.44 \pm 0.01^{c}$ & $2.19 \pm 0.20^{a}$ & $1.05 \pm 0.09$ & $1.05 \pm 0.05$ \\
\hline $\mathrm{PnT}+\mathrm{P}-\mathrm{ALA}$ & $21.54 \pm 0.83^{c}$ & $1.10 \pm 0.08^{c}$ & $0.45 \pm 0.03^{c}$ & $1.56 \pm 0.65^{\mathrm{a}}$ & $1.20 \pm 0.07^{d}$ & $0.89 \pm 0.12^{c}$ \\
\hline
\end{tabular}

Data are presented as Mean \pm S.E.M. Values with different superscripts $a, b, c, d$ are significantly different ( $p<0.05)$. GSH, reduced glutathione; SOD, superoxide dismutase; CAT, catalase; MDA, malondialdehyde; PMF, post mitochondrial fraction. PnT, parasitized; CQ, Chloroquine; ART, Artecxin; LON, Lonart; P-ALA, P-Alaxin. $\alpha=U / m g$ protein; $\mu=U / m g$ protein; $\pi=\mathrm{nmol} / \mathrm{mg} ; \Omega=\mu \mathrm{g} / \mathrm{mg}$ protein. 
Table 2. Assessment of liver mitochondrial membrane fluidity of $P$. berghei-infected mice treated with therapeutic doses of ART, CQ, LON and P-ALA.

\begin{tabular}{lccc}
\hline Treatments & Total protein $(\mathrm{g} / \mathrm{l})$ & Cholesterol $(\mathrm{mg} / \mathrm{dl})$ & Phospholipid $(\mathrm{mg} / \mathrm{dl})$ \\
\hline Control & $6.87 \pm 0.53^{\mathrm{a}}$ & $16.99 \pm 0.89^{\mathrm{a}}$ & $17.90 \pm 0.98^{\mathrm{a}}(0.95)$ \\
\hline PnT & $8.20 \pm 0.98^{\mathrm{a}}$ & $15.96 \pm 0.22^{\mathrm{a}}$ & $27.53 \pm 1.49^{\mathrm{b}}(0.58)$ \\
\hline PnT+CQ & $8.31 \pm 0.50^{\mathrm{a}}$ & $18.32 \pm 1.28^{\mathrm{a}}$ & $17.40 \pm 0.80^{\mathrm{a}}(1.05)$ \\
\hline PnT+ART & $4.86 \pm 0.43^{\mathrm{b}}$ & $19.97 \pm 1.41^{\mathrm{b}}$ & $22.79 \pm 1.30^{\mathrm{b}}(0.88)$ \\
\hline PnT+LON & $9.99 \pm 0.40^{\mathrm{c}}$ & $28.51 \pm 2.98^{\mathrm{c}}$ & $22.47 \pm 0.54 \mathrm{~b}(1.27)$ \\
\hline PnT+P-ALA & $10.18 \pm 0.25^{\mathrm{c}}$ & $19.97 \pm 1.13^{\mathrm{b}}$ & $24.17 \pm 1.23^{\mathrm{b}}(0.83)$ \\
\hline
\end{tabular}

Data are presented as Mean \pm S.E.M. Values in parentheses are cholesterol/phospholipid ratio. Values with different superscripts $a, b, c$ are significantly different $(p<0.05)$. PnT, parasitized non-treated; CQ, Chloroquine; ART, Artecxin; LON, Lonart; P-ALA, P-Alaxin

\section{The liver mitochondrial membrane composition of antimalarial-treated $P$. berghei-infected mice}

The composition of liver mitochondrial membranes of $P$. berghei-infected mice treated with ART and other antimalarial drugs were as presented in Table 2. The amount of total protein was non-significantly $(p>0.05)$ increased in the PnT- and CQ-treated mitochondrial membranes compared to that of healthy control mice. ART administration significantly $(p<0.05)$ decreased the mitochondrial membrane protein concentration by $41 \%$ and $29 \%$ compared to PnT and healthy mice, respectively. Significant $(p<0.05)$ increase was observed in the liver mitochondrial protein concentrations of LON $(22 \%)$ and P-ALA (24\%) compared to PnT; and 45\% and 48\% compared to healthy control mice, respectively. Similarly, the mitochondrial membrane cholesterol level was significantly increased $(p<0.05)$ in LON $(79 \%)$, ART $(25 \%)$ and PALA $(25 \%)$-treated mice compared to PnT-untreated mice but not significantly $(p>0.05)$ increased $(15 \%)$ in CQ-treated mice. Mitochondrial membrane cholesterol level was also non-significantly $(p>0.05)$ decreased $(-6 \%)$ in PnT mice compared to healthy control. However, mitochondrial membrane phospholipid was significantly $(p<0.05)$ increased in PnT $(54 \%)$ compared to healthy

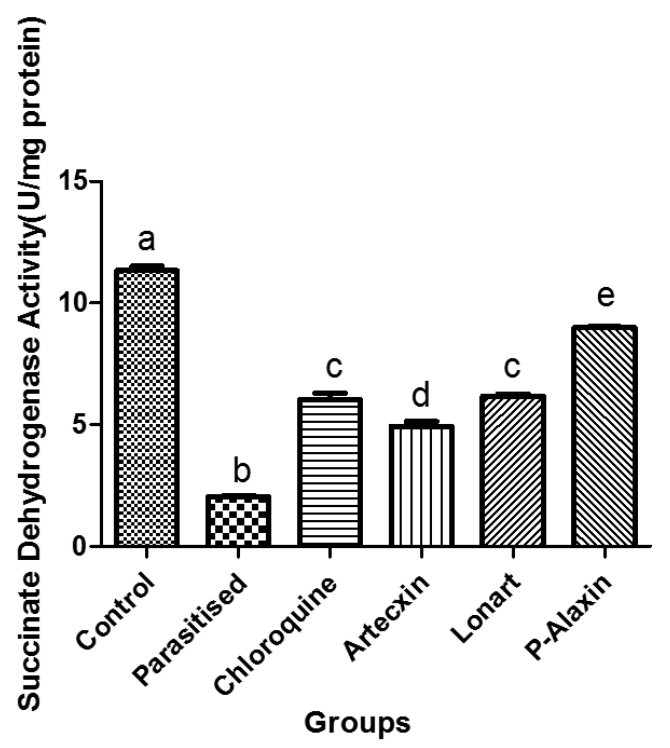

Figure 1. Assessment of succinate dehydrogenase activity in mitochondrial fraction of $P$. berghei-infected mice treated with antimalarial drugs

Data are presented as Mean \pm S.E.M. Values with different superscripts $\mathrm{a}, \mathrm{b}, \mathrm{c}, \mathrm{d}$ are significantly different $(p<0.05)$. control. There was no significant difference $(p<0.05)$ in the liver mitochondrial membrane phospholipids level of ART, LON and P-ALA -treated mice compared to parasitized mice, whereas CQ treatment significantly $(p<0.05)$ reduced the phospholipids to the basal level.

\section{Activity of hepatic mitochondrial succinate dehydrogenase in the PnT untreated and antimalarial-treated mice}

Figure 1 depicts the pattern of activity of hepatic mitochondrial succinate dehydrogenase in the PnT untreated and antimalarial-treated mice. Activity of succinate dehydrogenase was significantly decreased $(p<0.05)$ by not less than $80 \%$ in PnT untreated mice as compared to control. There were significant increases in succinate dehydrogenase activity of CQ- $(160 \%)$, Artecxin- $(100 \%)$, Lonart- $(140 \%)$ and P-Alaxin- $(200 \%)$ treated groups compared to PnT-untreated group.

\section{Body weight and relative organ weight of antimalarial-} treated $P$. berghei-infected mice

A significant $(p<0.05)$ reduction $(5.6 \%)$ of body weight of $P$. berghei-infected mice was obtained compared to healthy control. However, the reduction of the body weight of all the antimalarial-treated mice was not significant $(p>0.05)$ compared to healthy control mice and not significantly different from one another but significantly different from PnT-untreated mice (Table 3).

\section{DISCUSSION}

The mitochondria are vital organelles responsible for ATP synthesis via electron transport and oxidative phosphorylation, regulation of cell death and calcium homeostasis (Kroemer et al., 2007; Malhi et al., 2010; Cheng \& Ristow, 2013). During oxidative metabolism by the complexes I, III, or IV of the electron transport chain, reactive oxygen species (ROS) are produced when electrons prematurely reduce oxygen forming superoxide radical (Young et al., 2002; Nohl et al., 2005; Orrenius et al, 2007). Most of the ROS generated by the mitochondrial respiratory chain (MRC) are detoxified by the mitochondrial antioxidant enzymes, such as SOD2/MnSOD, in a physiologically healthy state (Lennon et al., 1991). In

Table 3. Effects of antimalarial drugs on liver and animal body weights

\begin{tabular}{lll}
\hline Groups & PCW (\%) & RLW \\
\hline Control & $2.03 \pm 0.42^{\mathrm{a}}$ & $0.011536 \pm 0.002^{\mathrm{a}}$ \\
\hline PnT & $-5.55 \pm 1.50^{\mathrm{b}}$ & $0.016887 \pm 0.001^{\mathrm{b}}$ \\
\hline PnT+CQ & $-1.86 \pm 0.24^{\mathrm{c}}$ & $0.014761 \pm 0.001^{\mathrm{b}}$ \\
\hline PnT+ART & $-1.70 \pm 0.50^{\mathrm{c}}$ & $0.012755 \pm 0.001^{\mathrm{b}}$ \\
\hline PnT+LON & $-1.65 \pm 0.42^{\mathrm{c}}$ & $0.008347 \pm 0.001^{\mathrm{a}}$ \\
\hline PnT+P-ALA & $-2.23 \pm 0.51^{\mathrm{c}}$ & $0.013419 \pm 0.001^{\mathrm{b}}$ \\
\hline
\end{tabular}

Data are presented as Mean \pm S.E.M. Values with different superscripts $a, b, c, d$ are significantly different $(p<0.05)$. PCW, percentage change in body weight; RLW, relative liver weight; $P n T$, parasitized; $C Q$, Chloroquine; ART, Artecxin; LON, Lonart; P-ALA, P-Alaxin. 
malaria infection, ROS have been demonstrated to be produced in the parasite's food vacuole during the digestion of host cell cytosol, and are able to diffuse from the parasite to the host cell compartment in erythrocyte (Atamna \& Ginsburg, 1993). These ROS formed by malaria parasites, if not checked by the host cyto-protective enzymes and antioxidants, can lead to oxidative damage thereby contributing to pathophysiology of many diseases as complications in malaria (Atamna \& Ginsburg, 1993). In this study malaria parasite infection markedly induced a state of oxidative stress in host (mice) as indicated by the significant decrease in post mitochondrial GSH level, SOD and CAT activities and increase in both mitochondrial and PMF MDA levels in parasitized nontreated mice (Table 1). These findings are in consonance with earlier reports on the rise in MDA level indicative of lipid peroxidation in the liver of $P$. berghei-infected mice and depletion in host's SOD and CAT activities being important features of malaria infections (Becker et al., 2004; Gora et al., 2006).

The mechanism of parasiticidal action of artemisinin derived antimalarials is claimed to involve its reaction with iron present in the heme prosthetic group of haemoglobin, leading to the generation of free radicals (prooxidants) that in turn kill the malaria parasites (Reis et al., 2010). It was first shown by Krungkrai \& Yuthavong (1987) that free radical scavengers antagonised the in vitro antimalarial activity of artemisinin-based combination drugs and free radical generators promoted them (Krishna et al., 2004). Subsequently, several studies on oxidants and antioxidants confirmed this relationship both in vitro and in vivo (Lavender et al., 1989; Meshnick et al., 1989; Senok et al., 1997). Treatment of membranes with artesunate (especially in the presence of heme) was also demonstrated to cause lipid peroxidation, a typical endproduct of free radical damage (Scott et al., 1989; Wei \& Sadrzadeh, 1994). Interestingly, all the tested antimalarial treatments significantly reversed the reduced level of GSH by over $100 \%$ and other biomarkers of oxidative stress to different extents while decreasing the extent of lipid peroxidation in both mitochondrial and post mitochondrial fractions of $P$. berghei-infected mice. These data suggests that oxidative stress plays a pivotal role in the pathogenesis of malaria infections and mode of action of the antimalarial drugs. The difference in composition of ART and P-ALA, CQ and LON did not pose any difference on their antioxidative stress effects except in the mitochondrial MDA levels. Indeed, these reductions of oxidative stress in parasitized mice treated with the antimalarial drugs are unique because the antimalarial drugs selectively attacked the parasitized red blood cells and reduced the extent of oxidative stress generated by the pathogenesis of malaria to the host (Table 1) via hemeiron mediated production of free radicals through activation of endoperoxide bridge of artemisinin compounds (Hunt \& Stocker, 1990).

Maintenance of both structural integrity of the cell and spatial separation of subcellular compartments are responsibilities of cell and organelles membrane phospholipids (Zinser et al., 1991). Many of the inner mitochondrial membrane proteins are involved in oxidative phosphorylation and their activity depends on the phospholipid composition of the membrane. Altered phospholipid composition affects mitochondrial respiration (Ohtsuka et al., 1993) as has been implicated in a variety of human diseases including Barth syndrome, ischemia, and heart failure (Chicco \& Sparagna, 2007; Joshi et al., 2009; Ribas et al, 2014). The role of the liver in the transmission process of malaria infection makes the mitochondrium a vital organelle that is not unlikely to be critically involved in the biochemical events leading to disease onset. Malaria infection seems to interfere with lipid metabolism as observed in decreased mitochondrial membrane cholesterol and elevated phospholipid in the present study. Mitochondrial membrane protein concentration was increased non-significantly $(p>0.05)$ by about $20 \%$ in $P$. berghei-infected mice liver. Treatment with antimalarial drugs further increased the levels of protein and cholesterol when compared with $P$. berghei-infected untreated mice except in the ART-treated group in which protein concentration was significantly $(p<0.05)$ decreased by $41 \%$. Thus, indicating that these drugs induced cholesterol and protein synthesis in the mitochondria (Table 2). The increased cholesterol level and phospholipid concentration observed in ACTs-treated groups compared to healthy control could possibly be a result of stimulation of cholesterol and phospholipid production by ACTs. The increase in synthesis of these lipids in the endoplasmic reticulum might have impacted their translocation/trafficking into the inner mitochondrial membrane (Table 2). Furthermore, the approximately 30\% reduction in protein concentration caused by ART treatment compared to healthy control suggests that certain enzymatic activities relating to mitochondrial function might be adversely affected. These variations in the composition of liver mitochondrial membrane resulted in substantial adjustments in membrane cholesterolphospholipid ratio to nearly basal level (Table 2). The low cholesterol - phospholipid ratio in the parasitized mice indicates extremely fluid and leaky membrane that might cause permeability as well as compromised mitochondrial membrane integrity. This seems to account for the elevations in plasma activities of AST, ALP and ALT in both parasitized and antimalarial-treated mice plasma in our previous study and thus confirmed that the hepatocyte membrane integrity and permeability are compromised during malaria infection and treatment with antimalarials (Adisa et al, 2016).

Succinate dehydrogenase (SDH) is an important mitochondrial enzyme complex that feeds electrons from the Krebs cycle into the respiratory chain (Ackrell et al., 1992, Lancaster et al., 2008). The activity of SDH was evaluated in this study to ascertain the resultant effects of the observed distortions in mitochondrial membrane fluidity and integrity. The decrease in succinate dehydrogenase activity observed in parasitized group could be a result of the proteolytic degradation of haemoglobin and uptake of oxygen by malaria parasite during infection resulting in decreased food transport, glycolysis, krebs cycle, oxygen tension and oxidative phosphorylation in host cells. Treatment of parasitized mice with the antimalarials ameliorated this parasitic effect (Fig. 1). There was $100 \%$ difference in SDH activity due to effects by P-ALA when compared to ART. This huge difference (2 folds) might be attributed to the presence of trimethoprim (antibiotic) in the composition of ART which might be interfering with the synthesis of $\mathrm{SDH}$ via the blockage of folate metabolism. Although, Fred and Ghee (2013) in their recent report showed that some antimalarial drugs e.g. Atovaquone selectively and irreversibly inhibit mitochondrial electron transport chain and parallel processes such as ATP synthesis in malaria parasite; findings from the present study clearly showed that antimalarials such as ART while eliciting their strong anti-parasiticidal activity could also reduce electron transfer in the respiratory chain and ultimately decrease ATP synthesis by the mitochondria in the host cells. This low 
ATP level may result in general weakness in patients during treatment with this drug.

The significant increase in liver weight in parasitized non-treated group coincides with report by Arinola and coworkers (2005) that Plasmodium berghei infection causes hepato- and splenomegalies in infected mice model and these were attributed to increased phagocytosis of infected cells by macrophages and deposition of malarial pigment as well as activation and hyperplasia of the reticulo-endothelial system during the disease (Sowunmi, 1996). However, the antimalarial drugs except LON could not substantially minimize the increase in liver weight probably due to the combined inductive action of the drugs on CYP450 synthesis and fatty changes (steatosis). The decrease in body weight of parasitized non-treated group could be the effects of nausea and dysgeusia (lack of appetite) associated with malaria disease. Consequently, the body cells switch to catabolic processes including proteolysis, glycogenolysis and lipolysis in the liver and peripheral tissues (e.g. muscle) in order to compensate for the hypoglycaemia and low reducing equivalents/ ATP (Onyesom \& Agho, 2011) to carry on other life sustaining activities. The net result is weight loss which further corroborates the observed decrease in SDH activity particular with ART treatment. Furthermore, the amelioration of the $P$. berghei-induced weight loss (Table 3) by the antimalarial drugs may be attributed to the generation of free radicals by the antimalarial drugs within the parasitized red blood cells which in turn kills them and reverse all the catabolic effects associated with $P$. berghei infection to the basal level gradually.

ART and other ACTs distort mitochondrial membrane composition thereby perturbing mitochondrial membrane fluidity. This phenomenon affects mitochondrial function via the reduction in succinate dehydrogenase activity and ultimately ATP synthesis. In particular Artecxin seems to reduce the parasitemia-induced oxidative stress. However, its adverse effects on membrane components and SDH activity suggests it should only be recommended for antimalarial treatment in severe cases of malaria infection when life saving option far outweighs the adverse effects of this drug.

\section{Conflict of interest}

The authors declare that there is no conflict of interest between them.

\section{REFERENCES}

Ackrell BAC, Johnson MK, Gunsalus RP, Cecchini G (1992) Structure and function of succinate dehydrogenase and fumarate reductase. In Chemistry and Biochemistry of Flavoproteins, Muller F ed, vol 3, pp 229-297, Boca Raton FL, CRC Press

Adisa RA, Sulaimon LA, Fabunmi A (2016) Toxicological and biochemical effects of therapeutic doses of Artecxin, Lonart and P-Alaxin in $P$. berghei-infected mice: A comparative study. Nig Qt J Hosp Med 26 (In press)

Akanbi OM, Odaibo AB, Afolabi KA, Ademowo OG (2009) AntiMSP-1(19) antibody (IgG) and reactive oxygen species (ROS) response against malaria infection in pregnancy in South Western Nigeria. Asian Pac J Trop Med 2: 9-15. doi: 20093149485

Arinola AG, Onubogu DI, Salimonu LS (2005) Spleen weight, liver weight and levels of circulating immune complexes in vitamin deficient mice infected with Plasmodium berghei. Afr J Clin Exp Microb 6: 95-99. doi: AJCEM/2004008/2516

Atamna H, Ginsburg H (1993) Origin of reactive oxygen species in erythrocytes infected with Plasmodium falciparum. Mol Biochem Parasitol 61: 231-241. https://doi.org/10.1016/0166-6851(93)90069-A

Becker K, Tilley L, Vennerstrom JL, Roberts D, Rogerson S, Ginsburg H (2004) Oxidative stress in malaria parasite-infected erythrocytes: Host-parasite interactions. Int J Parasitol 34: 163-189. doi: https:// doi.org/10.1016/j.ijpara.2003.09.011
Breman JG, Alilio MS, Mills A (2004) Conquering the intolerable burden of malaria: what's new, what's needed: a summary. Am J Tropical Med Hyg 71 (Suppl 2): 1815

Buege JA, Aust SD (1978) Microsomal lipid peroxidation. Methods Enzymol 52: 302-310. https://doi.org/10.1016/SOO76-6879(78)520326

Chen PS, Toribara TY, Warner H (1956) Micro determination of phosphorus. Analyt Chem 28: 1756-1758. doi:10.1021/ac60119a033

Cheng Z, Ristow M (2013) Mitochondria and metabolic homeostasis. Antioxid Redox Signal 19: 240-242. doi:10.1089/ars.2013.5255

Chicco AJ, Sparagna GC (2007) Role of cardiolipin alterations in mitochondrial dysfunction and disease. Am J Physiol Cell Physiol 292: C33-C44. doi: 101152/ajpcell.00243.2006

Egwunyenga AO, Isamah G, Nmorsi OP (2004) Lipid peroxidation and ascorbic acid levels in Nigeria children with acute falciparum malaria. Afri J Biotech 3: 560-563. doi: 10.5897AJB2004.000-2110

Farombi EO, Syntum YY, Emerole GO (2003) Influence of chloroquine treatment and $P$. falciparum malaria infection on some enzymatic and non-enzymatic anti-oxidant defense indices in humans. Drug Chem Toxicol 26: 59-71. doi: 10.1081/DCT-120017558

Fred MS, Ghee TT (2013) Natural Products with antimalarial activity. Phytochemistry and Pharmacognosy http://www.eolss.net/Eolss-sampleAllChapter.aspx

Geller BL, Winge DR (1983) A method for distinguishing Cu, Znand Mn-containing superoxide dismutases. Anal Biochem 128: 86-92. http://doi.org/10.1016/00003-2697(83)90348-2

Gora D, Sandhya M, Shiv G, Praveen S (2006) Oxidative stress, $\alpha$-tocopherol, ascorbic acid and reduced glutathione status in schizophrenics. Indian J Clin Biochem 21: 34-38. doi: 10.1016/j. tibs.2010.04.002

Greenberg J, Nadel EM, Coatney GR (1954) Differences in survival of several inbred strains of mice and their hybrids infected with Plasmodium berghei. J Infect Dis 95: 114-116. http://www.jstor.org/ stable/30100598

Hunt NH, Stocker R (1990) Oxidative stress and the redox status of malaria infected erythrocytes. Blood Cells 16: 499-526

Idonije OB, Festus O, Okhiai O, Akpamu, U (2011) Comparative study of the status of a biomarker of lipid peroxidation (Malondialdehyde) in patients with Plasmodium falciparum and Plasmodium vivax malaria infection. Asian J Biol Sci 4: 506-513. doi: 10.3923/ ajbs.2011.506.513

Johnson D, Lardy HA (1967) Isolation of liver or kidney mitochondria. Methods Ensymol 10: 94-96. https://doi.org/10.1016/00766879(67)10018-9

Jollow DJ, Mitchell JR, Zampaglione N, Gillete JR (1974) Bromobenzene induced liver necrosis: protective role of glutathione and evidence for 3,4 bromobenzene oxide as the hepatotoxic metabolite. Pharmacol 11: 151-169. doi: 100.1159/000136482

Joshi AS, Zhou J, Gohil VM, Chen S, Greenberg ML (2009) Cellular functions of cardiolipin in yeast. Biochim Biophys Acta 1793: 212-218. doi: 10.1016/j.bbamcr.2008.07.024

King TE (1967) Preparation of succinate dehydrogenase and reconstitution of succinate oxidase. Methods Ensymol 10: 322-331. https:// doi.org/10.1016/0076-6879(67)10061-X

Krishna S, Uhlemann A, Haynes RK (2004) Artemisinins: mechanism of action and potential for resistance. Drug Res Updates 7: 233-244. doi: 10.1016/j.drup.2004.07.001

Kroemer G, Galluzzi L, Brenner C (2007) Mitochondrial membrane permeabilization in cell death. Physiol Rev 87: 99-163. doi: 10.1152/ physrev.00013.2006

Krungkrai SR, Yuthavong Y (1987) The antimalarial action on Plasmodium falciparum of qinghaosu and artesunate in combination with agents which modulate oxidant stress. Trans Roy Soc Trop Med Hyg 81: 710-714. https://doi.org/10.1016/0035-9203(87)90003-4

Kulkarni AG, Suryakar AN, Sardeshmukh AS, Rathi DB (2003) Studies on biochemical changes with special reference to oxidant and antioxidants in malaria patients. Indian I Clin Biochem 18: 136-149. doi: 10.1007/BF02867380

Lancaster CRD, Herzog E, Juhnke HD, Madej MG, Müller FG, Paul R, Schleidt PG (2008) Electroneutral and electrogenic catalysis by dihaem-containing succinate:quinone oxidoreductases. Biochem Soc Trans 36: 996-1000. doi: org/10.1042/BST0360996

Lavender OA, Ager AL, Morris VC (1989) Quinghaosu dietary vitamin E, selenium and cod liver oil. Effect on susceptibility of mice to the malarial parasite Plasmodium yoelli. Am J Clin Nutr 5: 346-352

Lennon SV, Martin SJ, Cotter TG (1991) Dose dependent induction of apoptosis in human cell lines by widely diverging stimuli. Cell Prolif 24: 203-214. doi: 10.1111/j.1365-2184.1991.tb01150.x

Loria P, Miller S, Foler M, Tilley L (1999) Inhibition of peroxidative degradation of heme as the basis of action of chloroquine and other quinoline anti-malarials. Biochem J 339: 363-370. doi: 10.1042/ bj3390363

Lowry OH, Rosenbrough NJ, Farr AL, Randall RJ (1951) Protein measurement with Folin phenol reagent. J Biol Chem 193: 265-275 
Malhi H, Guicciardi ME, Gores GJ (2010) Hepatocyte death: a clear and present danger. Physiol Rev 90: 1165-1194. doi: 10.1152/physrev.00061.2009

Meshnick SR, Tsang TW, Lin FB, Pan HZ, Chang CN, Kuypers F, Chiu D, Lubin B (1989) Activated oxygen mediates the antimalarial activity of qinghaosu. Progr Clin Biol Res 313: 95-104

Misra HP, Fridovich I (1972) The role of superoxide anion in the autoxidation of epinephrine and a simple assay for superoxide dismutase. J Biol Chem 247: 3170-3175

Nohl H, Gille L, Staniek K (2005) Intracellular generation of reactive oxygen species by mitochondria. Biochem Pharmacol 69: 719-723. doi: 10.1016/j.bcp.2004.12.002

Ohtsuka T, Nishijima M, Suzuki K, Akamatsu YY (1993) Mitochondrialdysfunction of a cultured chinese hamster ovary cell mutant defient in cardiolipin. J Biol Chem 268: 22914-22919

Olayemi SO, Arikawe AP, Akinyede A, Oreagba AI, Awodele O (2012) Effect of malarial treatments on biochemical parameters and plasma $\mathrm{pH}$ of mice infected with Plasmodium berghei. Int J Pharmacol 8: 549-554. doi: 10.3923/ijp.2012.549.554

Onyesom I, Agho JE (2011) Changes in serum glucose and triacylglycerol levels induced by the co-administration of two different types of antimalarial drugs among some Plasmodium falciparum malarial patients in Edo - Delta region of Nigeria. Asian J Sci Res 4: 78-83. doi: 10.3923/ajsr.2011.78.83

Orrenius S, Gogvadze V, Zhivotovsky B (2007) Mitochondrial oxidative stress: implications for cell death. Annu Rev Pharmacol Toxicol 47: 143-183. doi: 10.1146/annurev.pharmtox.47.120505.105122

Pennacchio LA (2003) Insights from human/mouse genome comparisons. Mamm Genome 14: 429-436. doi: 10.1007/s00335-002-4001-1

Reis PA, Comim CM, Hermani F, Silva B, Barichello T, Portella AC, Gomes FCA, Sab IM, Frutuoso VS, Oliveira MF, Bozza PT, Bozza FA, Dal-Pizzol F, Zimmerman GA, Quevedo J, Castro-Faria-Neto HC (2010) Cognitive dysfunction is sustained after rescue therapy in experimental cerebral malaria, and is reduced by additive antioxidant therapy. PLoS Pathogens 6: 1-16. doi: 10.1371/journal.ppat.1000963

Ribas V, Garcia-Ruiz C, Fernandez-Checa JC (2014) Glutathione and mitochondria. Frontiers Pharmacol 5: 1-19. doi: 10.3389/ fphar.2014.00151

Rustin P, Munnich A, Roötig A (2002) Succinate dehydrogenase and human diseases: new insights into a well-known enzyme. Eur J Human Gen 10: 289-291. doi: 10.1038/sj.ejhg.5200793
Scott MP, Tamkun JW, Hartzell GW (1989) The structure and function of the homeodomain. $B B A$ Rev Cancer 989: 25-48. doi: 10.1016/0304-419X(89)90033-4

Sedlak J, Lindsay RH (1968) Estimation of total protein - bound and non protein sulfihydryl groups in tissue with Ellman's reagent. Anal Biochem 25: 192-205. doi: 10.1016/0003-2697(68)90092-4

Senok AC, Li K, Nelson EAS, Yu LM, Tian LP, Oppenheimer SJ (1997) Invasion and growth of Plasmodium falciparum is inhibited in fractionated thalassaemic erythrocytes. Trans Royal Soc Tropical Med Hyg 91: 138-143. doi: 10.1016/S0035-9203(97)90200-5

Sinha KA (1972) Colorimetric assay of catalase. Anal Biochem 47: 389394. doi: 10.1016/0003-2697(72)90132-7

Snow RW, Guerra CA, Noor AM, Myint HY, Hay SI (2005) The global distribution of clinical episodes of Plasmodium falciparum malaria. Nature 434: 214-217. doi: 10.1038/nature03342

Sowunmi A (1996) Hepatomegaly in acute falciparum malaria in children. Trans Royal Soc Tropical Med Hyg 90: 540-542. doi: 10.1016/ S0035-9203(96)90313-2

Vennerstrom JL, Nuzum EO, Miller RE, Dom A, Gerena L (1999) 8-Aminoquinolines active against blood stage Plasmodium falciparum in vitro inhibit hematin polymerization. Antimicrob Agent Chemother 43: 598-602. doi: 0066-4804/99/\$04.00+0

Wei N, Sadrzadeh SM (1994) Enhancement of hemin-induced membrane damage by Artemisinin. Biochem Pharmacol 48: 737-741. doi: 10.1016/0006-2952(94)90051-5

Yoshida S, Nagumo H, Yokomine T, Araki H, Suzuki A, Matsuoka H (2010) Plasmodium berghei circumvents immune responses induced by merozoite surface protein 1- and apical membrane antigen 1- based vaccines. PLoS One 5: e13727. doi: 10.1371/journal.pone.0013727

Young TA, Cunningham CC, Bailey SM (2002) Reactive oxygen species production by the mitochondrial respiratory chain in isolated rat hepatocytes and liver mitochondria: studies using myxothiazol. Arch Biochem Biophys 405: 65-72. doi: 10.1016/S00039861(02)00338-7

Zinser E, Sperka-Gottlieb CDM, Fasch E-V, Kohlwein SD, Paltauf F, Daum G (1991) Phospholipid synthesis and lipid composition of subcellular membranes in the unicellular eukaryote Saccharomyces cerevisiae. J Bacteriol 173: 2026-2034. doi: 10.1128/jb.173.6.20262034.1991 